\title{
Understanding patient perspectives on management of their chronic pain - online survey protocol
}

\author{
Manasi Gaikwad ${ }^{1,2}$ \\ Simon Vanlint ${ }^{\prime}$ \\ G Lorimer Moseley ${ }^{2,3}$ \\ Murthy N Mittinty ${ }^{4}$ \\ Nigel Stocks'
}

'Discipline of General Practice, School of Medicine, University of Adelaide, Adelaide, SA, ${ }^{2}$ Sansom Institute for Health Research, University of South Australia, Adelaide, SA, ${ }^{3}$ Neuroscience Research Australia, Sydney, NSW, ${ }^{4}$ School of Public Health, University of Adelaide, Adelaide, SA, Australia
Correspondence: Lorimer Moseley Sansom Institute for Health Research, University of South Australia, GPO Box 247I, Adelaide 500I, Australia

$\mathrm{Tel}+6 \mathrm{I} 883022454$

Fax +6I 883022853

Email lorimer.moseley@gmail.com
This article was published in the following Dove Press journal: Journal of Pain Research

22 December 2016

Number of times this article has been viewed

Background: It is widely recognized that both doctors and patients report discontent regarding pain management provided and received. The impact of chronic pain on an individual's life resonates beyond physical and mental suffering; equal or at times even greater impact is observed on an individual's personal relationships, ability to work, and social interactions. The degree of these effects in each individual varies, mainly because of differences in biological factors, social environment, past experiences, support, and belief systems. Therefore, it is equally possible that these individual patient characteristics could influence their treatment outcome. Research shows that meeting patient expectations is a major challenge for health care systems attempting to provide optimal treatment strategies. However, patient perspectives and expectations in chronic pain management have not been studied extensively. The aim of this study is to investigate the views, perceptions, beliefs, and expectations of individuals who experience chronic pain on a daily basis, and the strategies used by them in managing chronic pain. This paper describes the study protocol to be used in a cross sectional survey of chronic pain patients.

Methods and analysis: The study population will comprise of individuals aged $\geq 18$ years, who have experienced pain for $\geq 3$ months with no restrictions of sex, ethnicity, or region of residence. Ethics approval for our study was obtained from Humans research ethics committees, University of Adelaide and University of South Australia. Multinomial logistic regression will be used to estimate the effect of duration and character of pain, on patient's perception of time to recovery and supplement intake. Logistic regression will also be used for estimating the effect of patient-provider relationship and pain education on patient-reported recovery and pain intensity.

Discussion: Knowledge about the perceptions and beliefs of patients with chronic pain could inform future policies, research, health care professional education, and development of individualized treatment strategies.

Keywords: chronic pain, pain management, patient perspectives, survey, time to recovery

\section{Introduction}

The International Association for the Study of Pain (IASP) defines chronic pain as "pain that persists beyond the normal tissue healing time, usually $\geq 3$ months", in the absence of an obvious underlying biological cause. ${ }^{1}$ With nearly $20 \%$ of the population affected worldwide, chronic pain has become a disease in its own right, rather than just being considered a symptom. ${ }^{2-5}$ Furthermore, chronic pain is often associated with numerous physical and psychological complications such as disability, sleep disturbances, fatigue, depression, and social isolation. The traditional approach for managing an injury or other illness of diagnosis and treatment offers little hope to individuals experiencing 
chronic pain by trapping patients with chronic pain in a vicious cycle of trial and error treatments. Both patients and their doctors struggle with pain management with studies reporting a feeling of inadequacy about providing optimal treatment among physicians ${ }^{6-8}$ and dissatisfaction among patients concerning the treatments provided. ${ }^{9}$

Studies show that between $40 \%$ and $60 \%$ of the general population use dietary supplements to promote health and manage conditions. ${ }^{10-12}$ Approximately 33\% of those who use supplements quote pain as the primary reason. ${ }^{11}$ However little is known about their benefits as perceived by patients with chronic pain. Moreover, pain is a subjective sensory emotional experience, ${ }^{13}$ which may be influenced by an individual's biological, environmental, social, and psychological factors. Together with belief systems and expectations, these factors may also guide individual experiences, and influence treatment outcome(s). Even though studies report factors which predict chronic pain, ${ }^{14,15}$ their association with patients' perspectives of chronic pain and its management has not been studied extensively. In addition, meeting patients' expectations is an important objective for health care systems ${ }^{16}$ as it appears to improve treatment satisfaction between $8 \%$ and $25 \% .{ }^{17,18}$ Aligning patient expectations with a management plan can enhance treatment outcome and benefits.

Best practice insight recommends publishing a protocol prior to undertaking the study as it facilitates awareness of the research in progress. ${ }^{19}$ It also helps to maintain the transparency in reporting of the study. ${ }^{20,21}$ This paper describes the protocol and the questionnaire used in a cross-sectional survey of individuals who experienced pain for $\geq 3$ months.

\section{Aim and objectives}

The aim of this study protocol is to investigate the views, perceptions, beliefs, and expectations of individuals who experience chronic pain on a daily basis, and the strategies used by them in managing this pain. The objectives of this study protocol are to investigate if pain-related factors (such as duration and characteristics) and pain education, affects chronic pain patients' intake of supplements and perception of recovery. This study will also examine if health professionals support, and pain education to family and employer is related to pain intensity and perception of time for recovery in patients with chronic pain.

\section{Methods}

Design

An online survey method was selected for this study as it is cost-effective and easy to administer; unlike face-to-face interviewing, a survey provides a standardized approach allowing uniformity of questions asked to all participants. It also provides access to individuals without geographical dependency thus allowing the collection of rich data. ${ }^{22}$ Although online surveys may limit participation from individuals without access to the internet ${ }^{23}$ the advantages of this method have been shown to outweigh the disadvantages in terms of external validity. ${ }^{24}$

A questionnaire was designed specifically for this study following the checklist for reporting results of internet e-surveys (CHERRIES) protocol ${ }^{25}$ for the ethical reporting of surveys and was administered online using Survey Monkey. Ethics approval for this study was obtained from the Human Research Ethics Committee of the University of Adelaide (approval no: HREC-2016-0712) and the University of South Australia (application id: 0000035791).

\section{Recruitment}

The survey was advertised on multiple educational, basic, and clinical science websites and on social media in different countries, including Australia, Ireland, India, New Zealand and the US. Individuals accessing these websites were invited to participate in the study if they met the inclusion criteria. The survey was open for participants from all ethnicities and regions of residence. Data collection ceased by the end of October 2016. All participants activated an electronic consent prior to beginning the survey.

\section{Inclusion criteria}

Individuals for inclusion in the survey should be: 1) currently aged 18 years and above and 2) must have experienced pain $\geq 3$ months duration.

\section{Exclusion criteria}

Individuals are not eligible to participate in the survey if: 1) their current age is below 18 years; 2) they suffer from acute pain of $<3$ months duration; and 3) they do not consent to be a part of the survey study.

\section{Consent and confidentiality}

Individuals who click the link to participate in the study are first taken to an information page. The information page describes the proposed study, its relevance and also outlines what type of information will be asked from the participants and the time required to complete the survey. The information page notifies the participants that the survey is voluntary and their choice of participating or not participating will have no effect on their own pain management in any way. It also 
provides the participants with information regarding whom to contact in case of distress or if they have a complaint. The information page also explains that the survey is completely anonymous - information that could disclose the participant's identity is never asked at any stage during the survey.

\section{Data storage and handling}

The data was stored on a secure computer owned by University of Adelaide, with password-controlled access. Only the research team (all authors listed) had access to the data.

\section{Sample size}

Sample size calculations for estimation are based on three parameters, the variance or spread of the observations, the precision and the level of significance, or probability of type-1 error.

$$
n=\left(\frac{1.96^{2} P(1-P)}{\delta^{2}}\right)
$$

where $n=$ sample size, $P=$ estimated population proportion, $\delta=$ precision of the estimate.

For this sample size estimation, the values chosen were $P=0.5$ and $\delta=0.05$. Thus, it gives a sample size of 384 with $95 \%$ confidence interval and $80 \%$ power. This is the simple random sampling approach. ${ }^{26}$

\section{Questionnaire development}

Currently, there are very few studies examining the perspectives and the expectations of individuals who experience chronic pain regarding their pain management. Due to the unavailability of validated scales of chronic pain patients' perspectives, this questionnaire was developed by the team of authors through discussions and literature search. The questionnaire (Supplementary material) comprises of 5 sections and 39 items in total. A pilot study to verify the face and content validity of the questionnaire was conducted prior to finalizing it. ${ }^{27}$

\section{Analysis}

\section{Statistical analysis plan}

All analyses will be performed using STATA 14.1 Statistical software Release 12.

Multinomial logistic regression will be performed to estimate the effect of duration and character of pain; education about pain and variation in supplement intake on chronic pain patients' perception of time to recovery. Univariate logistic regression will be used to examine the effect of support received from health professionals, family, and employers on chronic pain patients pain levels, quality of life, and physical goals. The analysis will be adjusted for confounding factors such as age, sex, education, employment, and marital status.

Simple descriptive statistics such as mean, proportions, and variances will be described for the entire sample. Participants will be described in terms of pain duration, average length of their consulting time and frequency of visits, and satisfaction about their education and involvement in pain management.

\section{Measures}

\section{Dependent variables/outcomes}

1. Patients' perception of time to recovery. Information regarding participants' perceived time to recovery from their current pain problem will be collected.

2. Supplement intake. Information regarding each participant's intake of complementary medicines or dietary supplements (eg, calcium, magnesium, fish oil) and alternative medicines (eg, Chinese, herbal, Ayurvedic) will be collected, in addition to information regarding testing of vitamin D, vitamin D deficiency, and vitamin D supplementation.

\section{Independent variables/confounders}

1. Demographic data. Information regarding each participants' age, sex, area of residence, education, employment, and marital status will be collected.

2. Pain history. Information pertaining to each participants' history of current pain problem such as diagnosis received, duration, character, and intensity of pain will be collected.

3. Pain education. Information regarding method of education received, provider of education and influence of education on understanding, and management of pain will be collected.

4. Goals from pain management. The goals from pain management are classified into pain related outcomes; quality of life and physical functioning. Information pertaining to each classification will be collected.

5. Other variables. Information regarding each participant's most recent health care consultation, as well as information regarding provision of pain education to their family and employers, and its perceived impact on their recovery time will be collected.

\section{Dissemination}

The results from this survey analysis will be included as a chapter in MG's thesis and published in peer-reviewed 
scientific journals as well as used for conference presentations. The results of the study will be made available via the institutional websites.

\section{Discussion}

We aim to better understand whether patients' perspectives, views, and beliefs about their chronic pain management are associated, with perception of time to recovery and particularly with reference to testing and prescription of supplements. Moreover, the study has been promoted internationally and it is anticipated that the analysis will capture the variability of patients' perceptions and beliefs across countries (if the distribution of the sample obtained allows subgroup analysis). It is also expected that the results from the survey study will provide insight about what patients with chronic pain expect from their pain management and how these expectations are challenged by the duration of pain, the character of the pain, the quality of pain education, and support of health professionals. A deeper understanding of patients' perceptions with regards to their pain management will enable researchers, policy makers, and health professionals to design policies, interventions and prevention strategies which are tailored to individual patient needs and are intended to improve the treatment outcome.

This study will also provide information on intake of complementary and alternative medicines, dietary supplements, nonpharmacological therapies, and educational sources most frequently used by the chronic pain patients for managing their pain. It is also anticipated that this evidencebased knowledge will describe the self-management strategies most frequently implemented by chronic pain patients.

\section{Acknowledgment}

This research received no grant from any funding agency in the public, commercial, or not-for-profit sectors.

\section{Disclosure}

MG, SV, and NS declare that they have no conflicts of interest. MNM is funded by John Lynch's NHMRC Australian Fellow funding (ID 478115). GLM has received support from Pfizer, Kaiser Permanente, USA; Workers' Compensation Boards in Australia, North America, and Europe; Agile Physiotherapy, USA; Results Physiotherapy, USA; the International Olympic Committee and the Port Adelaide Football Club, Australia. He receives royalties for books on pain and rehabilitation, including two books that are cited in this article. He receives speaker fees for lectures on pain and rehabilitation. The author is supported by a Principal
Research Fellowship from the National Health and Medical Research Council of Australia.

\section{References}

1. Merskey H, Bogduk N. Classification of Chronic Pain. Seattle: IASP Press 1994.

2. Breivik H, Collett B, Ventafridda V, Cohen R, Gallacher D. Survey of chronic pain in Europe: prevalence, impact on daily life, and treatment. Eur J Pain. 2006;10(4):287-287.

3. Henderson JV, Harrison CM, Britt HC, Bayram CF, Miller GC. Prevalence, causes, severity, impact, and management of chronic pain in Australian general practice patients. Pain Med. 2013;14(9): $1346-1361$.

4. van Hecke O, Torrance N, Smith BH. Chronic pain epidemiology and its clinical relevance. Br J Anesth. 2013;111(1):13-18.

5. Blyth FM, March LM, Brnabic AJ, Jorm LR, Williamson M, Cousins MJ. Chronic pain in Australia: a prevalence study. Pain. 2001; 89(2):127-134.

6. Green CR, Wheeler JR, Marchant B, LaPorte F, Guerrero E. Analysis of the physician variable in pain management. Pain Med. 2001;2(4): 317-327.

7. Potter M, Schafer S, Gonzalez-Mendez E, et al. Opioids for chronic nonmalignant pain. J Fam Pract. 2001;50(2):145-145.

8. Upshur CC, Luckmann RS, Savageau JA. Primary care provider concerns about management of chronic pain in community clinic populations. J Gen Intern Med. 2006;21(6):652-655.

9. Turk DC, Wilson HD, Cahana A. Treatment of chronic non-cancer pain. The Lancet. 2011;377(9784):2226-2235.

10. Astin JA. Why patients use alternative medicine: results of a national study. JAMA. 1998;279:1548-1553.

11. Barnes PM, Powell-Griner E, McFann K, Nahin RL. Complementary and alternative medicine use among adults: United States, 2002. Semin Integr Med. 2004;2(2):1-19.

12. O'Dea JA. Consumption of nutritional supplements among adolescents: usage and perceived benefits. Health Educ Res. 2003;18(1): 98-107.

13. International Association for the Study of Pain. [webpage on the Internet]. Pain, IASP Pain Terminology. Available from: http://www.iasppain.org/Taxonomy?navItemNumber=576\#Pain. Accessed October 6, 2016.

14. Elliott AM, Smith BH, Penny KI, Smith WC, Chambers WA. The epidemiology of chronic pain in the community. Lancet. 1999;354(9186): $1248-1252$.

15. Torrance N, Smith BH, Bennett MI, Lee AJ. The epidemiology of chronic pain of predominantly neuropathic origin. Results from a general population survey. J Pain. 2006;7(4):281-289.

16. World Health Organization. The World Health Report-Health Systems: Improving Performance (Electronic edition). Geneva. 2001. Available from: http://www.who.int/entity/whr/2000/en/whr00_en.pdf?ua=1. Accessed March 10, 2016.

17. Oliver RL. Cognitive, affective, and attribute bases of the satisfaction response. J Consum Res. 1993;20(3):418-430.

18. Williams B. Patient satisfaction: a valid concept? Soc Sci Med. 1994;38(4):509-516.

19. Ohtake PJ, Childs JD. Why publish study protocols? Phys Ther. 2014;94(9):1208-12099.

20. West R. Trial protocols. Addiction. 2012 Sep 1;107(9):1544. Available from: http://onlinelibrary.wiley.com/doi/10.1111/j.13600443.2012.03989.x/full. Accessed March 10, 2016.

21. Ohtake PJ, Childs JD. Why publish study protocols? Physical Therapy. 2014;94(9):1208-1209.

22. Wyse SE. Advantages and Disadvantages of Surveys. Retrieved February 20 (2012): 2014. Available from: http://www.snapsurveys. $\mathrm{com} / \mathrm{blog} /$ advantages-disadvantages-surveys/. Accessed October 5, 2016 . 
23. Szolnoki G, Hoffmann D. Online, face-to-face and telephone surveys - comparing different sampling methods in wine consumer research. Wine Econ Policy. 2013;2(2):57-66.

24. Heen MS, Lieberman JD, Miethe TD. A comparison of different online sampling approaches for generating national samples. UNLV, Center for Crime and Justice Policy. 2014. University of Nevada, Las Vegas.
25. Eysenbach G. Improving the quality of Web surveys: the Checklist for Reporting Results of Internet E-Surveys (CHERRIES). J Med Internet Res. 2004;6(3):e34

26. Cochran WG. Sampling Techniques. Hoboken: John Wiley \& Sons, 2007.

27. Nardi PM. Doing Survey Research. Oxford: Routledge, 2015.

\section{Publish your work in this journal}

The Journal of Pain Research is an international, peer reviewed, open access, online journal that welcomes laboratory and clinical findings in the fields of pain research and the prevention and management of pain. Original research, reviews, symposium reports, hypothesis formation and commentaries are all considered for publication.

\section{Dovepress}

The manuscript management system is completely online and includes a very quick and fair peer-review system, which is all easy to use. Visit http://www.dovepress.com/testimonials.php to read real quotes from published authors. 